\title{
BMJ open Hookah's new popularity among US college students: a pilot study of the characteristics of hookah smokers and their Facebook displays
}

\author{
Libby N Brockman, ${ }^{1,2}$ Megan A Pumper, ${ }^{3}$ Dimitri A Christakis, ${ }^{1}$ Megan A Moreno ${ }^{3}$
}

To cite: Brockman LN , Pumper MA, Christakis DA, et al. Hookah's new popularity among US college students: a pilot study of the characteristics of hookah smokers and their Facebook displays. BMJ Open 2012;2: e001709. doi:10.1136/ bmjopen-2012-001709

- Prepublication history for this paper are available online. To view these files please visit the journal online (http://dx.doi.org/10.1136/ bmjopen-2012-001709).

Received 8 August 2012 Revised 25 October 2012 Accepted 25 October 2012

This final article is available for use under the terms of the Creative Commons Attribution Non-Commercial 2.0 Licence; see http://bmjopen.bmj.com

${ }^{1}$ Center for Child Health Behavior and Development, Seattle Children's Research Institute, Seattle, Washington, USA

${ }^{2}$ Department of Health Services, School of Public Health, University of Washington, Seattle, Washington, USA

${ }^{3}$ Department of Pediatrics, University of Wisconsin, Madison, Wisconsin, USA

\section{Correspondence to}

Libby N Brockman; Libby. brockman@seattlechildrens. org

\begin{abstract}
Objectives: (1) To confirm the prevalence of hookah use among US college students. (2) To identify substances commonly smoked in hookahs and other substance use characteristics of hookah smokers.

(3) Given the powerful influence of Facebook and its potential role in promoting behaviours, to assess the prevalence of hookah references on Facebook profiles. Design: Cross-sectional study.

Setting: Two large US universities; www.Facebook.com.
\end{abstract}

Participants: 307 Facebook profiles were coded and 216 of these profile owners completed an online survey. On average, participants were 18.8 years old $(\mathrm{SD}=0.7)$, women $(54 \%)$, Caucasian $(70.4 \%)$ and approximately half were from each university.

Outcome measures: Lifetime and frequency of hookah use, substance smoked in hookah, cigarette and marijuana use, hookah references displayed on Facebook.

Results: $27.8 \%$ of participants endorsed hookah use; there were no significant differences between age, gender, race or university for hookah use. Hookah users reported smoking tobacco $(78 \%)$, hash $(12 \%)$ and both tobacco and marijuana/hash (10\%) in their hookah. Compared with non-hookah smokers, hookah smokers were more likely to report using cigarettes (OR=3.41, $95 \% \mathrm{Cl}=1.2$ to 9.64 ) and marijuana $(\mathrm{OR}=15.01,95 \% \mathrm{Cl}=6.5$ to 34.65$)$. Hookah references were present on $5 \%$ of Facebook profiles.

Conclusions: More than one quarter of college students smoke hookah. Most smoke tobacco in their hookah, and hookah smoking is associated with polysubstance use. Hookah may present new risks for nicotine addiction in this population.

\section{INTRODUCTION}

Tobacco use is the leading preventable cause of morbidity and mortality worldwide. Encouragingly, public health efforts have successfully decreased the prevalence of cigarette smoking in the USA by half over the past 45 years. ${ }^{1}$ This achievement is attributed

\section{ARTICLE SUMMARY}

Article focus

- To confirm the prevalence of hookah use among US college students.

- To identify characteristics of US college student smokers, including substances typically smoked in a hookah.

- To determine the prevalence of hookah references on Facebook profiles belonging to US college students.

Key messages

- Hookah smoking is becoming increasingly popular and more than $25 \%$ of college students smoke hookah.

- Hookah smoking is significantly associated with cigarette and marijuana use, and some college students smoke marijuana in their hookah.

- Some college students reference hookah on their Facebook profiles.

Strengths and limitations of this study

- This is the first study to examine what substances college hookah smokers use in their hookah, and the presence of hookah references on Facebook.

- The validity of hookah references on Facebook remains unknown.

to the first Surgeon General's report on smoking and health in 1964, taxation, indoor smoking bans, media advertising restrictions and counter-advertising campaigns, and increased public awareness of the harms associated with cigarette smoking. ${ }^{2}$

Despite this laudable public health accomplishment, the use of alternative forms of tobacco is currently rising, threatening these successful efforts. Of particular concern is the increasing popularity of hookah. ${ }^{3}$ Hookah use, also known as shisha, narghile and waterpipe, is defined as the smoking of substances through a waterpipe such that the smoke passes through water and is cooled 
prior to inhalation. Smoking a waterpipe is a tradition dating back at least four centuries to origins in northern Africa and southwest Asia. ${ }^{4}$ Until recently, smoking in this fashion remained primarily a tradition observed in Middle Eastern countries, most popular among adult men. ${ }^{5}$

At present, hookah smoking is becoming an increasingly popular form of tobacco use worldwide. Spreading from the Eastern Mediterranean region, hookah use is now common in Western countries including Australia, the UK, Canada and the USA. ${ }^{3}$ Further, hookah is becoming increasingly popular among youth. A recent global surveillance study examining time trends (19992008) of tobacco use in youth found an increase in hookah smoking among teens as young as 13-year-olds to 15 -year-olds. ${ }^{3}{ }^{6}$ In the USA, adolescents and young adults are at the forefront of this resurgence.

The understanding of hookah-smoking patterns among youth remains incomplete. Current estimates suggest that $15-41 \%$ of undergraduate college students smoke hookah. ${ }^{7-11}$ Further, while hashish or opium were once smoked in hookahs in the Middle East and India, ${ }^{5} 12$ smoking tobacco in hookahs was popularised in the 1990s with the introduction of maasel, a sweetened and flavoured tobacco product. ${ }^{3}$ Some reports suggest marijuana, hashish or other drugs are sometimes added to hookah tobacco. ${ }^{13}$ However, the predominate substances smoked in hookahs and other substance use practices of hookah users among US teens remain unknown.

Therefore, the primary purpose of this pilot study was to confirm the lifetime prevalence of hookah smoking among undergraduate students at two large public universities in different regions of the USA. The second aim of this study was to identify the specific substance use practices of hookah smokers, including the predominant substance that young adults smoke in their hookah, and other substance use characteristics of hookah smokers. Identifying these characteristics of hookah smokers has numerous public health and clinical implications, and is a necessary step in developing targeted prevention and intervention strategies.

Finally, how and why hookah smoking is gaining popularity among young adults also remain unclear. Many attribute hookah's popularity to its social nature; hookah use is a shared, communal experience and two or more people often share a single waterpipe. ${ }^{46}$ It is also possible that new forms of media are playing a role in promoting hookah smoking among young adults. Recent work suggests hookah-related videos on YouTube, compared with cigarette-related videos, are less likely to reference the harmful consequences of smoking or provide antismoking messages. ${ }^{14}$ As cultivation theory suggests, online videos may influence viewers' opinions and perceptions; videos that fail to portray the negative consequences of hookah smoking may serve to promote this behaviour among young adults. ${ }^{15}$

The authors hypothesise that social networking websites (SNSs) may also popularise hookah smoking by serving as a venue in which young adults learn about and promote hookah use among their social groups. In recent years, SNSs such as Facebook have become a tremendously popular source of social media among adolescents and young adults; Facebook is now used by over $90 \%$ of college students and is the most popular SNS among university students. ${ }^{16}$ While previous studies have found associations between consuming media, such as television and movies, depicting tobacco and the initiation of tobacco use, it has been argued that Facebook may have greater influence than traditional media because Facebook combines the power of interpersonal persuasion with the reach of mass media. ${ }^{17}{ }^{18}$ Specifically for adolescents and young adults, for whom peers are the most important source of influence, the power of interpersonal persuasion cannot be underestimated. ${ }^{19}$ Some suggest that these websites may serve as a media 'super-peer' by promoting norms of behaviour among adolescents. ${ }^{20}$ Additionally, social learning theory predicts that adolescents observe, imitate and model behaviours they see in their peers.

Thus, the third objective of this study was to conduct a pilot investigation of the presence of hookah references on Facebook. As a social networking site, Facebook may provide a venue for peer interaction and social networking, both of which are recognised as contributors to risk behaviours. ${ }^{21}$ Risk behaviours such as alcohol and drug use have been found to be displayed on SNS profiles. ${ }^{21}$ It is therefore possible that hookah is also displayed online within social networks, but the extent to which this is so remains unknown.

\section{METHODS}

This study was conducted between September 2009 and December 2011 and received IRB approval from both the University of Wisconsin and the University of Washington.

\section{Setting}

Participants for this study attended one of two large, public universities, in the Midwest and on the West Coast. Participants were recruited via the social networking website Facebook (www.Facebook.com). This SNS was selected because it is the most popular SNS among the target population of college students. ${ }^{22}$

\section{Subject selection}

The Facebook search engine was used to identify random public profiles registered within either university network that listed a graduation year indicating the profile owner was a freshman, sophomore or junior student. Inclusion criteria required profile owners to report an age on their profile between 18 and 20 years and to show evidence of profile activity within the last 30 days.

All profiles returned in the search results were assessed sequentially for eligibility. Profiles were 
excluded if they did not meet search criteria (ie, incorrectly listed), including those who were not undergraduates $(\mathrm{N}=448)$, did not meet the age criteria $(\mathrm{N}=313)$ or did not display their age $(\mathrm{N}=49)$. Profiles were also excluded if their profiles were completely private, had any one of the following sections set to private: information section, wall or photographs $(\mathrm{N}=1630)$, or if the profile owner was not reachable for recruitment (ie, no phone number or email listed on Facebook profile or in the university directory) ( $\mathrm{N}=303)$. In order to reach a target survey sample size of 200 participants, a total of 307 eligible Facebook profiles were identified in 2009 and 2010 and invited to participate in the study. Demographic data were recorded from eligible profiles.

\section{Recruitment}

The 307 profile owners with profiles that met inclusion criteria were called on the phone. The phone call served two purposes. First, profile owner's identity and age were verified. Second, eligible students were then recruited to participate in the online survey. Survey invites were only sent to profile owners whose identity could be confirmed over the phone. The study was explained to the profile owner and permission was requested to send an email that contained further information about the study. If the participant consented to receive the email, an email was sent that provided detailed information about the study as well as a link to an online survey. The survey was administered online via a Catalyst WebQ online survey engine. Survey respondents were provided a $\$ 15$ iTunes gift card as compensation.

\section{Survey}

The online survey evaluated hookah use. Participants were asked about their lifetime experience using hookah. Those who reported ever using hookah were also questioned about their frequency of use; answer options included never, monthly or less, 2-4 times a month, 2-3 times a week, 4 or more times a week. Participants were also asked what substances they typically smoked in their hookah; answer options included tobacco, marijuana, hash, a mix of marijuana/hash and tobacco. All participants were also questioned about their lifetime experience and frequency of use of marijuana and cigarettes, with similar answer options for frequency as described above.

\section{Facebook profile coding}

To investigate the presence of hookah references on college students' Facebook profiles, all 307 profiles were evaluated once by one of three trained coders using a research codebook. This codebook has been previously used to evaluate the display of other health-risk behaviour references on SNS profiles such as alcohol and violence. $^{23}{ }^{24}$ The codebook was adapted for this study to code for references to hookah. In order to determine whether hookah references were present, coders viewed all publicly accessible elements of the Facebook profile including profile owners' tagged pictures, profile pictures, information sections and their Wall. Both images and text were coded and hookah reference data included the coder's typewritten description of any image references or verbatim text from profiles usually found in the form of status updates or in the Info Section. If present, identifiable information was removed from text references. One year of profile data were assessed for each participant, starting from the date of evaluation and going back to the same date, 1 year prior.

Profiles were categorised into one of two groups. Profiles with one or more references to hookah use were classified as hookah 'Displayers'. Example references included personal photographs in which the profile owner was smoking a hookah, or text references describing smoking hookah. Only photographs that contained the profile owner with a clearly identifiable hookah and text references that explicitly mentioned the word hookah or a synonym of hookah, such as shisha or narghile, were coded. Profiles without any hookah references were considered 'Non-Displayers'.

Because of infrequent references to hookah on Facebook, inter-rater agreement was used to assess coder reliability. A $20 \%$ random subsample of profiles was evaluated by all three coders and $96 \%$ inter-rater reliability was achieved.

\section{Analysis}

Demographic characteristics, frequency and prevalence of hookah use and Facebook displays of hookah were summarised using descriptive statistics. Bivariate logistic regression was used to examine covariates of lifetime hookah use (outcome); ORs and their 95\% CI were obtained for independent variables including age, gender, race/ethnicity, university and substance use. A multivariate model of lifetime hookah use was also fit, including the covariates of age, gender, race/ethnicity, university and substance use. Bivariate comparisons between demographic characteristics and hookah Displayer/Non-Displayer groups were conducted using Fisher's exact tests and $\chi^{2}$ tests. All statistical analyses were conducted using STATA V.11.0 (Statacorp, College Station, Texas, USA). A two-sided $p$ value $p<0.05$ was considered statistically significant.

\section{RESULTS}

\section{Subjects}

A total of 307 Facebook profiles were coded; 216 (70\% response rate) of these individuals completed all survey questions with viable answers and were included in the analyses. Participants had an average age of 18.8 years (SD 0.7), were $54.2 \%$ women and $70.4 \%$ Caucasian. Approximately half of participants were from each university. See table 1 for further details. 


\begin{tabular}{|c|c|c|c|}
\hline \multirow[b]{2}{*}{ Variable } & \multicolumn{3}{|l|}{ Per cent (n) } \\
\hline & Total & Hookah non-users $(n=156)$ & Hookah users $(n=60)$ \\
\hline \multicolumn{4}{|l|}{ Age (years) ${ }^{*}$} \\
\hline 18 & $35.7 \%(77)$ & $36.5 \%(57)$ & $33.3 \%(20)$ \\
\hline 19 & $50.9 \%(110)$ & $48.1 \%(75)$ & $58.3 \%(35)$ \\
\hline 20 & $13.4 \%(29)$ & $15.4 \%(24)$ & $8.33 \%(5)$ \\
\hline \multicolumn{4}{|l|}{ Gender } \\
\hline Male & $47.2 \%(102)$ & $45.5 \%(71)$ & $51.7 \%(31)$ \\
\hline Female & $52.8 \%(114)$ & $54.5 \%(85)$ & $48.3 \%(29)$ \\
\hline \multicolumn{4}{|l|}{ State } \\
\hline Washington & $46.8 \%(101)$ & $47.4 \%(74)$ & $45.0 \%(27)$ \\
\hline Wisconsin & $53.2 \%(115)$ & $52.6 \%(82)$ & $55.0 \%(33)$ \\
\hline \multicolumn{4}{|l|}{ Race/ethnicity $†$} \\
\hline Caucasian & $70.4 \%(150)$ & $68.0 \%(104)$ & $76.7 \%(46)$ \\
\hline African American & $0 \%$ & $0 \%$ & $0 \%$ \\
\hline Asian/Pacific Islander & $18.8 \%(40)$ & $20.9 \%(32)$ & $13.3 \%(8)$ \\
\hline Hispanic & $2.3 \%(5)$ & $2.6 \%(4)$ & $1.7 \%(1)$ \\
\hline Other/multiracial & $8.5 \%(18)$ & $8.5 \%(13)$ & $8.3 \%(5)$ \\
\hline
\end{tabular}

*Overall mean (SD), $18.8(0.7)$ years.

†Three missing values.

\section{Survey results}

Prevalence of hookah use

Lifetime hookah use was reported by $27.8 \%(\mathrm{~N}=60)$ of participants (table 2). Participants who reported ever using hookah were on average 18.8 (SD 0.6) years of age, and tended to be men $(51.7 \%)$ and Caucasian (76.7\%; table 1). There were no significant differences between age, gender, race or university for hookah use. Of those who reported ever smoking hookah, 78.3\% smoked hookah monthly or less and $21.6 \%$ were current users who reported smoking hookah more than once per month.

\section{Substances smoked in the hookah}

More than three-quarters $(78 \%)$ of those who reported ever smoking hookah reported primarily smoking tobacco in their hookah. Only $12 \%$ reported smoking only hash in their hookah, while $10 \%$ reported smoking both marijuana/hash and tobacco in their hookah. A total of $22 \%$ reported using a hookah to smoke marijuana.

Table 2 Survey results: endorsement of substance use

\begin{tabular}{llll}
\hline & \multicolumn{2}{l}{ Per cent $(\mathbf{n})$} \\
\cline { 2 - 4 } Variable & Total & $\begin{array}{l}\text { Hookah } \\
\text { non-users }\end{array}$ & $\begin{array}{l}\text { Hookah } \\
\text { users } †\end{array}$ \\
\hline Hookah & $27.8 \%(60)$ & $0 \%$ & $100 \%(60)$ \\
Cigarettes & $16.2 \%(35)$ & $7.1 \%(11)$ & $40 \%(24)$ \\
Marijuana & $30.7 \%(66)$ & $13.6 \%(21)$ & $75 \%(45)$ \\
\hline${ }^{*} n=156$. & & \\
$\dagger n=60$. & & \\
$\ddagger T$ Three missing values. &
\end{tabular}

\section{Hookah users engagement with other substances}

Of those who reported ever using hookah, $40 \%$ reported ever smoking cigarettes, of whom $42.7 \%$ reported smoking cigarettes more than once a month. Most $(75 \%)$ hookah users reported ever using marijuana, of whom $51 \%$ reported using marijuana more than once per month. No hookah users endorsed cigarette use only; all hookah smokers who smoked cigarettes also smoked marijuana (table 3).

Multivariate modelling of lifetime hookah use indicated that those who endorsed hookah use were more likely to report other substance use. Hookah users were more likely to use cigarettes $(\mathrm{OR}=3.41, \mathrm{p}<0.05)$ and marijuana $(\mathrm{OR}=15.01, \mathrm{p}<0.001)$ compared with nonhookah smokers (table 4).

\section{Facebook results}

Hookah references were present on $5.3 \%$ of Facebook profiles. There were no significant differences in hookah display between gender, race or university. Examples of hookah references included personal images of profile owners smoking a hookah, downloaded imagines of icons saying 'I \ HOOKAH', or status updates such as 'Tonight is a hookah type of night, I love nights like these' and 'Skippin' class all day, goin' hookah shopping, fun!'

\section{DISCUSSION}

This study explored characteristics of college student hookah smokers and evaluated the presence of hookah references displayed on university students' public Facebook pages. More than one-quarter of college students reported smoking hookah and this prevalence 
Table 3 Survey results: endorsement of substance use by hookah use

\begin{tabular}{lllll}
\hline \multirow{2}{*}{ Variable } & Per cent $(\mathbf{n})$ & & & \\
\cline { 2 - 4 } & Cigarettes only & Marijuana only & Cigarettes and marijuana & None \\
\hline Hookah users $(n=60)$ & 0 & $35 \%(21)$ & $40 \%(24)$ & $25 \%(15)$ \\
Hookah non-users $(n=155)^{*}$ & $4.5 \%(7)$ & $11 \%(17)$ & $2.5 \%(4)$ & $82 \%(127)$ \\
\hline${ }^{*}$ One missing value. & & & &
\end{tabular}

estimate is consistent with the national estimate of hookah use among young adults enrolled in college. ${ }^{25}$ To the authors' knowledge, this is the first study to survey college students about what substances they smoke in their hookah. The majority of hookah smokers reported smoking tobacco in their hookah, yet more than $20 \%$ reported experience with using marijuana or hash in their hookah. These findings support the rising popularity and diversity of hookah use among young adults in the USA.

The finding that so many college students are smoking hookah, and specifically smoking tobacco in their hookah, is cause for clinical and public health concern. Although the health effects of hookah have not been studied nearly as extensively as cigarettes, smoking tobacco in a waterpipe is associated with negative health outcomes similar to those associated with cigarette use. Studies compare hookah to cigarettes and illustrate that both forms of tobacco use expose smokers to toxicants associated with cardiovascular and lung disease, including carbon monoxide and polycyclic aromatic hydrocarbons. ${ }^{3} 26$ Further, hookah use significantly increases one's risk of lung cancer, respiratory illness, low birthweight and periodontal disease. ${ }^{27}$ Lastly, preliminary research shows hookah use may be associated with nicotine dependence and could be a gateway drug to cigarette smoking. ${ }^{3} 28$

These negative health consequences of hookah use are compounded by the many misperceptions and incorrect beliefs and attitudes held by hookah users. Many hookah smokers underestimate the health risks and addictive properties of hookah use. In contrast to the published harms of hookah use, college students and young adults believe smoking tobacco in a waterpipe is less harmful and less addictive than cigarettes and believe they can quit anytime. ${ }^{29} 30$

Similar to other studies, the results of this study suggest that hookah users were more likely than nonhookah users to engage in substance use (separate from their hookah smoking) such as marijuana, cigarettes and other psychoactive drugs. ${ }^{10} 3132$ Due to the crosssectional nature of this study, it is impossible to determine the temporal sequence of hookah smoking and the use of other substances. However, it may not be surprising that hookah smokers also engage in other substance use behaviours. Previous research supports that engagement in one risk behaviour is often associated with an increased likelihood of engaging in other risk behaviours. ${ }^{33}$ This may be especially true for hookah, cigarettes and marijuana, all different means of smoking. It may be that once a college student decides to engage in a smoking behaviour, they may be open to a variety of smoking behaviours. These results suggest hookah prevention efforts may be paired with other substance use and general smoking prevention strategies.

The findings that one in five hookah smokers smoke marijuana in their hookah and that hookah smokers are more likely to smoke marijuana separately compared to non-hookah smokers, are important for two reasons. First, given that many college students maintain that hookah smoking is a safe alternative to cigarette smoking and that hookah smoking does not constitute 'smoking', ${ }^{11}$ it is possible that these young adults differentiate between methods of tobacco use. Similarly,

Table 4 Multivariate logistic regression modelling of lifetime hookah use $(n=216)$

\begin{tabular}{lll}
\hline Variable & Unadjusted OR (95\% Cl) & Adjusted OR† (95\% Cl) \\
\hline Age & $0.92(0.58$ to 1.44$)$ & $0.86(0.47$ to 1.57$)$ \\
Gender & $0.78(0.43$ to 1.42$)$ & $1.22(0.55$ to 2.70$)$ \\
Race & Reference group & Reference group \\
$\quad$ Caucasian & $0.57(0.24$ to 1.32$)$ & $0.59(0.18$ to 1.99$)$ \\
Asian/Pacific Islander & $0.57(0.60$ to 5.20$)$ & $0.19(0.02$ to 2.45$)$ \\
Hispanic & $0.87(0.29$ to 2.58$)$ & $2.25(0.58$ to 8.75$)$ \\
Other/multiracial & $1.1(0.61$ to 2.00$)$ & $0.95(0.40$ to 2.26$)$ \\
University & $8.79(3.94$ to 19.59$)$ & $3.41(1.20 \text { to } 9.64)^{*}$ \\
Cigarettes & $19.14(9.10$ to 40.27$)$ & $15.01(6.50 \text { to } 34.65)^{*}$ \\
Marijuana & &
\end{tabular}


college students may have altered perceptions of the safety of smoking marijuana in a hookah. Second, given the integration of hookah smoking into the social scene on college campuses, ${ }^{11}$ it is possible that marijuana may also experience a sort of social promotion when associated with hookah. This may have implications for intervention strategies and further work is needed to explore these ideas.

To the best of the authors' knowledge, this is also the first study to investigate hookah use using Facebook. These findings show more than $5 \%$ of college student profiles display references to hookah on Facebook. While this percentage does not compare with the prevalence of smoking hookah, hookah references on SNSs have not yet been extensively studied. Other work illustrates that adolescents display references to other risk behaviours such as alcohol and substance use on their SNS profile. ${ }^{21}$ These displays of various risk behaviours may represent engagement in that behaviour, consideration of engagement in the behaviour, boastful claims or nonsense. ${ }^{21}$ College students who display references to intoxication or problem drinking on their Facebook profile were more likely to meet clinical criteria for problem drinking compared to those who do not display such references. ${ }^{34}$ In addition, adolescents interpret alcohol displays on SNSs to be influential and valid representations of alcohol use. ${ }^{35}$ Thus, these displays are meaningful. Given the social nature of hookah smoking, the social dimension of Facebook may be a salient factor in popularising hookah use. Since students mainly initiate and practice hookah use with friends, Facebook may allow them to find such friends. Further research exploring the presence and meaning of specifically hookah displays on Facebook profiles is necessary.

There are several potential limitations to this study. First, participants were recruited from only two universities and the study sample included very few minority and no African American participants. While the study sample is demographically representative of the student population at the two selected universities, it is possible that these two universities do not provide a representative sample of the US college population. The literature suggests that after students of Arab descent, Caucasian students, followed by Asian students have the highest reported prevalence rates of smoking hookah. ${ }^{11}$ Therefore, given that the participants were selected from large geographically distinct state universities and that these prevalence estimates are consistent with other studies' estimates, this suggests that these results may be generalisable to the US college population. Second, only profiles from one SNS were evaluated and participants were limited to those who maintained a public Facebook profile and allowed their phone numbers to be listed in either their university directory or on Facebook. The extent to which these findings could be generalised to profiles that have their security set to private, to profiles on other SNSs, or to younger adolescent populations is not known. Third, it is important to note that SNS profile privacy settings are not permanent; profile owners may change their privacy settings at any time or to reflect what security upgrades are offered by Facebook. It is unclear as to whether profile owners who maintained a private profile at the time of this study would be more likely, or less likely, to display hookah references. Lastly, the cross-sectional design of this study precluded determining the temporal sequence of smoking hookah and engagement in other substance use. Future research including longitudinal studies is needed to explore these associations, especially the potential role of hookah as a gateway to cigarette smoking.

Despite these limitations, the findings have important implications. First, this is the first study to illustrate that hookah use goes beyond tobacco. College students also smoke marijuana and hash in their hookah. With this understanding, future prevention and intervention methods may pair existing tobacco and marijuana strategies when targeting college hookah smokers. Second, hookah use is also emerging on Facebook profiles, which may help promote the illusion that it is a socially acceptable behaviour and safe alternative to cigarettes. To determine if hookah references aid in the promotion of hookah smoking among college students, more work is needed to explore the presence and meaning of hookah displays on Facebook. Further, similar to studies which have found Facebook to be feasible for identifying college students at risk for problem drinking, more work is needed to determine if SNSs may also be helpful for screening and identifying college students at risk for or engaged in hookah smoking.

Acknowledgements The authors would like to thank Hope Villiard and Lauren Kacvinsky for their assistance with data collection.

Contributors As the first author, LNB contributed to this paper by designing the project, and by acquiring, analysing and interpreting the data for this study. LNB also provided statistical expertise and drafted the manuscript. MAP actively participated in data collection, and provided technical support as well as a critical revision of the manuscript for important intellectual content. DAC provided statistical expertise, administrative/technical/material support, and critical revisions of the manuscript for important intellectual content. MAM contributed to this paper by providing conception and design efforts, funding, administrative/technical/material support, supervision and a critical revision of the manuscript for important intellectual content.

Funding This work was supported by award R211AA017936 from NIAAA as well as award K12HD055894 from the Eunice Kennedy Shriver National Institute of Child Health and Human Development.

Competing interests None.

Ethics approval IRBs at the University of Wisconsin and the University of Washington.

Provenance and peer review Not commissioned; externally peer reviewed.

Data sharing statement There are no additional unpublished data from this study.

\section{REFERENCES}

1. CDC. Trends in current cigarette smoking among high school students and adults, United States, 1965-2010: Centers for Disease Control \& Prevention. 2011. 
2. Warner KE, Mendez D. Tobacco control policy in developed countries: yesterday, today, and tomorrow. Nicotine Tob Res 2010;12:876-87.

3. Maziak W. The global epidemic of waterpipe smoking. Addict Behav 2011;36:1-5.

4. Regulation WSGoTP. Advisory note: waterpipe tobacco smoking: health effects, research needs, and recommended actions by regulators. Geneva, Switzerland: World Health Organiztion, Tobacco Free Initiative, 2005.

5. Kandela P. Nargile smoking keeps Arabs in Wonderland. Lancet 2000;356:1175.

6. Warren CW, Lea V, Lee J, et al. Change in tobacco use among 13-15-year-olds between 1999 and 2008: findings from the Global Youth Tobacco Survey. Glob Health Promot 2009;16(2 Suppl):38-90.

7. Primack BA, Sidani J, Agarwal AA, et al. Prevalence of and associations with waterpipe tobacco smoking among U.S. university students. Ann Behav Med 2008;36:81-6.

8. Fielder RL, Carey KB, Carey MP. Prevalence, frequency, and initiation of hookah tobacco smoking among first-year female college students: a 1-year longitudinal study. Addict Behav 2012;37:221-4.

9. Braun RE, Glassman T, Wohlwend J, et al. Hookah use among college students from a midwest university. J Community Health 2012;37:294-8.

10. Sutfin EL, McCoy TP, Reboussin BA, et al. Prevalence and correlates of waterpipe tobacco smoking by college students in North Carolina. Drug Alcohol Depend 2011;115:131-6.

11. Grekin ER, Ayna D. Waterpipe smoking among college students in the United States: a review of the literature. J Am Coll Health 2012;60:244-9.

12. Ray C. The hookah-the Indian waterpipe. Curr Sci 2009;96:1319-23.

13. Knishkowy $B$, Amitai $Y$. Water-pipe (narghile) smoking: an emerging health risk behavior. Pediatrics 2005;116:e113-19.

14. Carroll MV, Shensa A, Primack BA. A comparison of cigarette- and hookah-related videos on YouTube. Tob Control 2012. Published Online First.

15. Gerbner G, Gross L, Morgan M, et al. Living with television: the dynamics of the cultivation process. In: Bryant J, Zillman D, eds. Perpsectives on media effects. Hillsdale, NJ: Lawrence Erlbaum Associates, 1986:17-40.

16. Lewis K, Kaufman J, Christakis N. The taste for privacy: an analysis of college student privacy settings in an online social network. $J$ Comput-Mediated Commun 2008;14:79-100.

17. Mass Interpersonal Persuasion: An Early View of a New Phenomenon. Third International Conference on Persuasive Technology. Berline: Springer, 2008

18. Dalton MA, Beach ML, Adachi-Mejia AM, et al. Early exposure to movie smoking predicts established smoking by older teens and young adults. Pediatrics 2009;123:e551-8.
19. Neinstein L, Anderson M. Adolescent development. In: Neinstein L, ed. Adolescent health care: a practical guide. Philadelphia: Lippincott Williams and Wilkins, 2002:767-92.

20. Strasburger VC, Wilson BJ, Jordan A. Children, adolescents and the media. Beverly Hills: Sage, 2008.

21. Moreno MA, Parks MR, Zimmerman FJ, et al. Display of health risk behaviors on MySpace by adolescents: prevalence and associations. Arch Pediatr Adolesc Med 2009;163:35-41.

22. Buffardi LE, Campbell WK. Narcissism and social networking Web sites. Pers Soc Psychol Bull 2008;34:1303-14.

23. Moreno MA, Egan KG, Brockman L. Development of a researcher codebook for use in evaluating social networking site profiles. $J$ Adolesc Health 2011;49:29-35.

24. Moreno M, Parks M, Zimmerman F, et al. Display of health risk behaviors on MySpace by adolescents: prevalence and associations. Arch Pediatr Adolesc Med 2009;163:27-34

25. ACHA ACHA. National College Health Assessment II: reference group executive summary, Spring 2011. Hanover, MD: American College Health Association, 2011.

26. Shihadeh A, Saleh R. Polycyclic aromatic hydrocarbons, carbon monoxide, "tar", and nicotine in the mainstream smoke aerosol of the narghile water pipe. Food Chem Toxicol 2005;43:655-61.

27. Akl EA, Gaddam S, Gunukula SK, et al. The effects of waterpipe tobacco smoking on health outcomes: a systematic review. Int $J$ Epidemiol 2010;39:834-57.

28. Jensen PD, Cortes R, Engholm G, et al. Waterpipe use predicts progression to regular cigarette smoking among Danish youth. Subst Use Misuse 2010;45:1245-61.

29. Smith-Simone S, Maziak W, Ward KD, et al. Waterpipe tobacco smoking: knowledge, attitudes, beliefs, and behavior in two U.S. samples. Nicotine Tob Res 2008;10:393-8.

30. Smith SY, Curbow B, Stillman FA. Harm perception of nicotine products in college freshmen. Nicotine Tob Res 2007;9:977-82.

31. Dugas E, Tremblay M, Low NC, et al. Water-pipe smoking among North American youths. Pediatrics 2010;125:1184-9.

32. Eissenberg T, Ward KD, Smith-Simone S, et al. Waterpipe tobacco smoking on a U.S. College campus: prevalence and correlates. J Adolesc Health 2008;42:526-9.

33. Fox HB, McManus MA, Arnold KN. Significant multiple risk behaviors among U.S. High School Students. Fact Sheet No. 8March 2010. Washington, DC: The National Alliance to Advance Adolescent Health, 2010.

34. Moreno MA, Christakis DA, Egan KG, et al. Associations between displayed alcohol references on Facebook and problem drinking among college students. Arch Pediatr Adolesc Med 2011;166:157-63.

35. Moreno MA, Briner LR, Williams A, et al. Real use or "real cool": adolescents speak out about displayed alcohol references on social networking websites. J Adolesc Health 2009;45:420-2. 